\title{
Effect of polybrominated diphenyl ether (PBDE) treatment on the composition and function of the bacterial community in the sponge Haliclona cymaeformis
} \author{
Rudolf Shiu Sun Wu $\mathbf{W u}^{3,4}$ and Pei-Yuan Qian ${ }^{1,4 *}$ \\ ${ }^{1}$ Divison of Life Science, The Hong Kong University of Science and Technology, Hong Kong, China \\ 2 Department of Biology, Hong Kong Baptist University, Hong Kong, China \\ ${ }^{3}$ School of Biological Sciences, The University of Hong Kong, Hong Kong, China \\ ${ }^{4}$ State Key Laboratory of Marine Pollution, The City University of Hong Kong, Hong Kong, China
}

Ren-Mao Tian ${ }^{1}$, On On Lee ${ }^{1}$, Yong Wang ${ }^{1}$, Lin Cai ${ }^{1}$, Salim Bougouffa ${ }^{1}$, Jill Man Ying Chiu ${ }^{2}$,

Edited by:

Ute Hentschel, University of

Wuerzburg, Germany

Reviewed by:

Jan S. Suchodolski, Texas A\&M

University, USA

Zhiyong Li, Shanghai Jiao Tong

University, China

*Correspondence:

Pei-Yuan Qian, Division of Life

Science, The Hong Kong University

of Science and Technology, Clear

Water Bay, Hong Kong, China

e-mail: boqianpy@ust.hk
Marine sponges play important roles in benthic environments and are sensitive to environmental stresses. Polybrominated diphenyl ethers (PBDEs) have been widely used as flame retardants since the 1970s and are cytotoxic and genotoxic to organisms. In the present study, we studied the short-period effect of PBDE-47 $\left(2,2^{\prime}, 4,4^{\prime}\right.$-tetrabromodiphenyl ether) treatment on the community structure and functional gene composition of the bacterial community inhabiting the marine sponge Haliclona cymaeformis. Our results showed that the bacterial community shifted from an autotrophic bacteria-dominated community to a heterotrophic bacteria-dominated community in response to PBDE-47 in a time- and concentration-dependent manner. A potentially symbiotic sulfur-oxidizing bacterium (SOB) was dominant ( $>80 \%$ in abundance) in the untreated sponge. However, exposure to a high concentration $(1 \mu \mathrm{g} / \mathrm{L})$ of PBDE-47 caused a substantial decrease in the potential symbiont and an enrichment of heterotrophic bacteria like Clostridium. A metagenomic analysis showed a selective effect of the high concentration treatment on the functional gene composition of the enriched heterotrophic bacteria, revealing an enrichment for the functions responsible for DNA repair, multidrug efflux pumping, and bacterial chemotaxis and motility. This study demonstrated that PBDE-47 induced a shift in the composition of the community and functional genes in the sponge-associated bacterial community, revealing the selective effect of PBDE-47 treatment on the functions of the bacterial community in the microenvironment of the sponge.

Keywords: PBDEs, sponge-associated bacterial community, 16S rRNA gene pyrosequencing, metagenomics, symbionts

\section{INTRODUCTION}

Marine sponges arose 600 million years ago and are the most primitive metazoans found worldwide (Li et al., 1998). They constitute a major component of benthic communities in marine environments and play an essential role in the marine ecosystem in terms of pelagic processes (Dayton et al., 1974; Dayton, 1989) such as the food chain and silicon cycle. Interestingly, marine sponge can form close associations with the symbiotic microbial communities within their bodies (Taylor et al., 2007), and thus, the symbiotic microbial community is sponge-specific and distinct from those in the surrounding seawater and other habitats (Taylor et al., 2007; Lee et al., 2011). Symbiotic microorganisms play essential roles in the sponge body, participating in carbon, nitrogen, and sulfur cycles (Taylor et al., 2007).

Sponge-microbe consortia are sensitive to environmental stresses such as metal pollutants and heat stresses. Recent studies have shown that the sponge-associated microbial community composition can be shifted in response to heat stress and copper treatment (Webster et al., 2001, 2008; Fan et al.,
2013; Tian et al., 2014b). In a case study, the bacterial community of the sponge Rhopaloeides odorabile was dominated by Proteobacteria, Actinobacteria, Nitrospira, Acidobacteria and Chloroflexi, whereas at a high temperature, the main population changed to Proteobacteria, Bacteroidetes and Firmicutes, some of which are pathogenic (Webster et al., 2008). In a second case study, copper treatment resulted in morphological changes in the associated microbes of $R$. odorabile. Moreover, the copper treatment shifted the bacterial community composition, resulting in an enrichment for phylogenetically distant bacterial species (Webster et al., 2001).

Since the 1970s, polybrominated diphenyl ethers (PBDEs) have been widely used as flame retardants in plastics, textiles, polyurethane foam and electrical and electronic appliances, and thus, they have become ubiquitous in some environments. The presence of $22 \mathrm{PBDE}$ congeners in cod, ringed seal, polar bear, and beluga whale in the Arctic have been detected during the last decade (Wolkers et al., 2004). Severely contaminated sediment in the San Francisco Bay could harbor PBDEs at concentrations up 
to $212 \mathrm{ng} / \mathrm{g}$ (Shaw and Kannan, 2009). A study examining blubber biopsy samples from whales raised high concerns that PBDEs may be transferred along the marine food chain, posing a threat to marine mammals, especially to prominent predators (Rayne et al., 2004).

The harmful effects of PBDEs have been documented in marine invertebrates such as polychaetes, gastropods and barnacles in terms of morphology, growth and settlement (Lam et al., 2010; Chiu et al., 2012). In addition, studies have shown that PBDEs can disrupt the levels and the balance of sex and thyroid hormones in vertebrates (Tomy et al., 2004; Han et al., 2011). The cytotoxic and genotoxic effects of PBDE-47 have been demonstrated in vitro in human neuroblastoma (SH-SY5Y) cells. In those studies, PBDE-47 inhibited cell viability, enhanced lactate dehydrogenase leakage, and induced cell apoptosis (Zhang and Huang, 2005; He et al., 2008; Yan et al., 2011). PBDE209 (decabromodiphenyl ether) was also found to be antiproliferative and to induce apoptosis in tumor cells in vitro (Zhang and Huang, 2005). Moreover, the genotoxicity of five PBDE congeners was investigated in chicken DT40 cells, including wild type and mutant cell lines that were deficient in DNA repair pathways. It was found that DT40 cells that were deficient in base excision repair and translation DNA synthesis pathways were hypersensitive to tetra-BDEs and hydroxyl-tetra-BDEs (Ji et al., 2011). Other studies have also demonstrated that PBDEs can covalently bind to DNA mediated by quinone metabolites, forming PBDE-DNA adducts with the potential to damage DNA (Zhao et al., 2002).

Whereas previous studies on the toxicity of PBDEs have mainly focused on vertebrates, mussels, and various eukaryotic cell lines, the effects of PBDEs on sponges and associated microbes are unknown. In this study, we investigated the short-period effects of low and high concentration of PBDE-47 (a dominant congener that is potentially more toxic than others) on the community composition and functional gene profile of microbes inhabiting the marine sponge Haliclona cymaeformis, to examine how PBDE-47 will shift the bacterial communities and what genetic features will assist the survival of the enriched bacteria under the stress induced by this pollutant.

\section{MATERIALS AND METHODS COLLECTION OF SPONGE SPECIES}

In the present study, we used the sponge Haliclona cymaeformis, which is a commonly found sponge species in Hong Kong. Intact and healthy sponge colonies were collected from shallow water (at a depth of $\sim 1 \mathrm{~m}$ ) at Po Toi O Village, Hong Kong $\left(22^{\circ} 16^{\prime} 32.96^{\prime \prime} \mathrm{N}, 114^{\circ} 17^{\prime} 39.95^{\prime \prime} \mathrm{E}\right)$ and transported back to the laboratory in natural seawater. The sponge colonies were then maintained in an aquarium supplied with circulating sandfiltered seawater and sufficient aeration for 1 week to stabilize the sponges prior to experimentation. Colonies of H. cymaeformis comprise independent gemmules (each with one osculum) that characterize the clonal budding mode of reproduction (Figure S1).

\section{TREATMENT OF THE SPONGE SAMPLES WITH PBDE-47}

In this study, we investigated the short-period effects of low $(10 \mathrm{ng} / \mathrm{L}$, a typical concentration in polluted seawater) and high
$(1 \mu \mathrm{g} / \mathrm{L}$, a representative concentration in seriously polluted areas like sediment) doses of PBDE-47 over 2 and 6 days, respectively (based on preliminary experiments, data not shown). A stock solution of PBDE-47 (>99\% purity, Chem Service, Inc., West Chester, PA) at $3 \mathrm{mg} / \mathrm{mL}$ was prepared by dissolving the chemical in dimethyl sulfoxide (DMSO), which was then further diluted to $10 \mathrm{ng} / \mathrm{L}$ and to $1 \mu \mathrm{g} / \mathrm{L}$ in seawater. A solvent control group (DMSO at $1 \mu \mathrm{L} / \mathrm{L}$ ) and negative control group (seawater alone) were used.

Using denaturing gradient gel electrophoresis (DGGE), a preliminary screening of the bacterial community showed highly similar band patterns of the different sponge colonies (data not shown). Therefore, we used one large sponge colony as starting material and cut it into 27 small colonies (each with 2-3 complete gemmules) for the experiments (similarly to a study of sponges exposed to heat stress, Webster et al., 2008). The small colonies were placed in 2-L aquariums supplied with $1.5 \mathrm{~L}$ of filtered seawater with the corresponding PBDE-47 concentrations and sampled at 0,2, and 6 days. Figure S2 provides a detailed description of the treatment. The room temperature was stabilized at $22-25^{\circ} \mathrm{C}$ to ensure an appropriate water temperature for the sponges.

\section{DNA EXTRACTION OF SPONGE SAMPLES}

Sponge tissues were sampled on days 0,2 , and 6 of the treatment period. At each time point, three sponge colony replicates from each group were sampled, and intact gemmules of the colonies were cut into small pieces using sterile stainless steel scissors. The samples were further homogenized with a sterilized mortar and pestle to release the microorganisms. The homogenates were centrifuged at $100 \times \mathrm{g}$ for $1 \mathrm{~min}$ to pellet the debris and fragments of sponge tissues. The supernatant was then filtered through a $12-\mu \mathrm{m}$ filter membrane (GE Water \& Process Technologies). The filtrate of microorganisms was stained with safranin (Bacto Laboratories Pty Ltd.) and observed under a $100 \times$ microscope (Olympus BX51, USA). Most of the filtered microorganisms were $\sim 1 \mu \mathrm{m}$ in size, indicating that nearly all of the eukaryotic cells had been removed from the filtrate. The filtrate was then centrifuged at $10,000 \times \mathrm{g}$ for $5 \mathrm{~min}$, and the pellets, presumably containing the microbial cells, were stored in $800 \mu \mathrm{L}$ of DNA extraction buffer (500 mM NaCl, $50 \mathrm{mM}$ Tris- $\mathrm{HCl}$ [pH 8], $40 \mathrm{mM}$ EDTA, $0.75 \mathrm{M}$ sucrose). DNA extraction was conducted according to a previous protocol (Lee et al., 2009). Briefly, the bacteria were lysed using $10 \mu \mathrm{L}$ of lysozyme $(100 \mathrm{mg} / \mathrm{mL})$, and the protein was digested using $80 \mu \mathrm{L}$ of $20 \%$ SDS and $8 \mu \mathrm{L}$ of proteinase $\mathrm{K}(10 \mu \mathrm{g} / \mu \mathrm{L})$. DNA was extracted twice with chloroform:isoamyl alcohol (24:1) and then precipitated with 100\% isopropanol followed by washing in $75 \%$ cold ethanol. The quality and quantity of the extracted DNA were checked using a NanoDrop ND-1000 device (Thermo Fisher, USA) and agarose gel electrophoresis.

\section{PCR AMPLIFICATION OF THE 16S rRNA GENE FOR PYROSEQUENCING}

The hypervariable V3-V5 region of the $16 \mathrm{~S}$ rRNA gene was amplified using the primer set $341 \mathrm{~F}$ ( $5^{\prime}$ CCTACGGGAGGCAGCAG $\left.3^{\prime}\right)$ and 907R (5' CCGTCAATTCCTTTRAGTTT 3'). A unique 8nucleotide barcode was added to both primers for multiplexed pyrosequencing using barcrawl (Pourmand et al., 2002; Frank, $2009)$. Each $20-\mu \mathrm{L}$ PCR reaction consisted of $4 \mu \mathrm{L}$ of $5 \times$ Phusion 
HF Buffer (M0530S New England BioLabs Inc.), 1.6 $\mu \mathrm{L}$ of dNTPs (2.5 $\mu \mathrm{M}$ each), $1 \mu \mathrm{L}$ of each primer $(10 \mu \mathrm{M}), 0.6 \mu \mathrm{L}$ of DMSO, $10 \mathrm{ng}$ of template DNA, $0.2 \mu \mathrm{L}$ of Phusion ${ }^{\circledR}$ High-Fidelity DNA Polymerase ( 0.4 units) and $10.6 \mu \mathrm{L}$ of pure water. PCR was performed with a thermal cycler (Bio-Rad, USA) using the following program: an initial denaturation at $98^{\circ} \mathrm{C}$ for $1 \mathrm{~min} ; 25$ cycles at $98^{\circ} \mathrm{C}$ for $10 \mathrm{~s}, 60^{\circ} \mathrm{C}$ for $30 \mathrm{~s}$ and $72^{\circ} \mathrm{C}$ for $20 \mathrm{~s}$; and a final extension at $72^{\circ} \mathrm{C}$ for $5 \mathrm{~min}$. The PCR products were detected by agarose gel electrophoresis, and the purified concentrations were measured using a NanoDrop ND-1000 device (Thermo Fisher, USA). Equal amounts of the barcoded amplicons were mixed and pyrosequenced using a ROCHE 454 FLX Titanium platform.

\section{ANALYSIS OF THE 16S rRNA GENE SEQUENCES}

The pyrosequencing datasets were analyzed using the Quantitative Insights Into Microbial Ecology (QIIME) pipeline (Caporaso et al., 2010b). The sequences were filtered using the following quality controls: sequences with a quality score $<25$; homopolymers with a length $>6,<100$, or $>1000 \mathrm{bp} ;>6$ ambiguous bp; $>3$ mismatches in the primer and 1 mismatch in the barcodes. Qualified sequences were sorted into their corresponding samples according to the unique barcodes. The reads were further subjected to a denoising program (using greedy scheme algorithm) for a second round of quality control (Reeder and Knight, 2010). The OTUs were selected at the species level with 3\% dissimilarity, and each OTU was assigned using the Ribosomal Database Project (RDP) Classifier (version 2.2) (Wang et al., 2007) with the Silva10.8 database (Pruesse et al., 2007) with a confidence level of 50\%. Representative sequences of each OTU were aligned using MUSCLE (Edgar, 2004) and PyNAST (Caporaso et al., 2010a). Chimeric sequences identified by Chimera Slayer (Caporaso et al., 2010a) were removed. Similarities among the bacterial communities were evaluated by UniFrac Principal Coordinates Analysis (PCoA). A UniFrac Jackknife tree was constructed to display the relationships of the bacterial community in each sample. The statistical significance of the pairwise sample dissimilarity was assessed by the $P$-test.

A phylogenetic tree of a potentially symbiotic bacterium (unassigned Ectothiorhodospiraceae) was constructed using Mega 6.05 based on the partial 16S rRNA gene and reference sequences from NCBI (hits from the NR/NT database with an identity $>95 \%$, which mainly included unculturable bacteria, and hits from the $16 \mathrm{~S}$ rRNA sequence database with an identity $>85 \%$, which included identified species).

\section{METAGENOMIC SEQUENCING AND ANALYSIS}

The metagenomic DNA of the two replicates ( $1 \mu \mathrm{g}$ each) of sample D6 (DMSO control for the 6-day treatment) and H6 (6-day high-dose treatment) was equally pooled and used for Roche 454 shotgun pyrosequencing. Quality control was conducted for the raw metagenomic DNA sequences using the NGS QC Toolkit (version 2.3) (Patel and Jain, 2012) to remove sequences with an average quality score less than 20, a read length less than 100 bp and homopolymers of more than $6 \mathrm{bp}$. Sequences containing ambiguous bases of more than $5 \mathrm{bp}$, including the ambiguous bases, were further trimmed. Artificial Duplicate Reads were removed using the program CD-HIT-454 (Niu et al., 2010).
Qualified reads were used for a blast analysis (BLAST 2.2.27) against the COG database (http://string-db.org/; version 9.1). The best hits, with an $E$-value $>1$ e-5, bit score $>100$ and alignment length $>30 \%$ of the query, were selected as the functional annotation of the reads. Comparison of the functional profiles of pairwise samples was performed with STAMP (Parks and Beiko, 2010) using the pairwise comparison method and Fisher's exact test followed by Storey FDR correction as previously described (Mason et al., 2012).

\section{NUCLEOTIDE SEOUENCE SUBMISSION}

The data for the $16 \mathrm{~S}$ rRNA amplicon and metagenomic sequencing for the PBDE-47 treatment experiment were submitted to the Sequence Read Archive (SRA) database of NCBI under accession numbers SRP018357 and SRP038119, respectively.

\section{RESULTS}

PBDE-47 AFFECTED SPONGE-ASSOCIATED BACTERIAL COMMUNITIES IN A CONCENTRATION- AND TIME-DEPENDENT MANNER

After 16S rRNA gene amplicon pyrosequencing, a total of 216,656 raw sequences were obtained, of which 164,747 (average length of $519 \mathrm{bp}$ ) were recovered by quality control as clean data for subsequent analysis. Rarefaction analysis based on the number of operational taxonomic units (OTUs) and the Shannon index (Figure S3, Table S1) revealed that the sequencing depth was sufficient and that the overall bacterial communities were well described.

The similarity of the sponge-associated bacterial communities was calculated and displayed using Principal Coordinate Analysis (PCoA, Figure S4) and UPGMA clustering analysis (Figure 1). In the PCoA analysis, PC1, which explained $55 \%$ of the observed variations, separated H6 from the remaining samples; PC2 explained $31 \%$ of the variations and separated the 6-day samples from the 0- and 2-day samples. H6 was distant in comparison to the other samples, and a pairwise statistical test indicated that the bacterial communities from the two H6 samples (H6.1 and H6.2) were significantly different ( $P$-test; $p<$ $0.01)$ from all of the other samples. In the Jackknife UPGMA tree (Figure 1), N0, N2, and L2 clustered together and H2 emerged as an independent group (but with a relatively low dissimilarity). For the 6-day samples, N6, D6, and L6 were in the same cluster and $\mathrm{H} 6$ was located a large distance from all of the other samples. Taken together, these results indicated that PBDE-47 shifted the bacterial communities in the sponge in a concentration- and time-dependent manner.

\section{PROTEOBACTERIA DECREASED WHILE FIRMICUTES WERE ENRICHED DURING THE TREATMENT}

Altogether, 17 phyla were recovered from the sponge bacterial communities (Figure 2A). The untreated samples were dominated by Proteobacteria (97.6\%). In the 2-day treatment samples, the low- and high-concentration-treated samples (L2 and H2) showed a similar community structure compared with the negative control (N2) and the solvent control (D2), indicating that the treatment had a slight effect within 2 days. In the 6-day samples, however, the Proteobacteria decreased from $82.2 \%$ (in D6) to $71.4 \%$ in L6 and $41.7 \%$ in H6. In contrast, the Firmicutes 


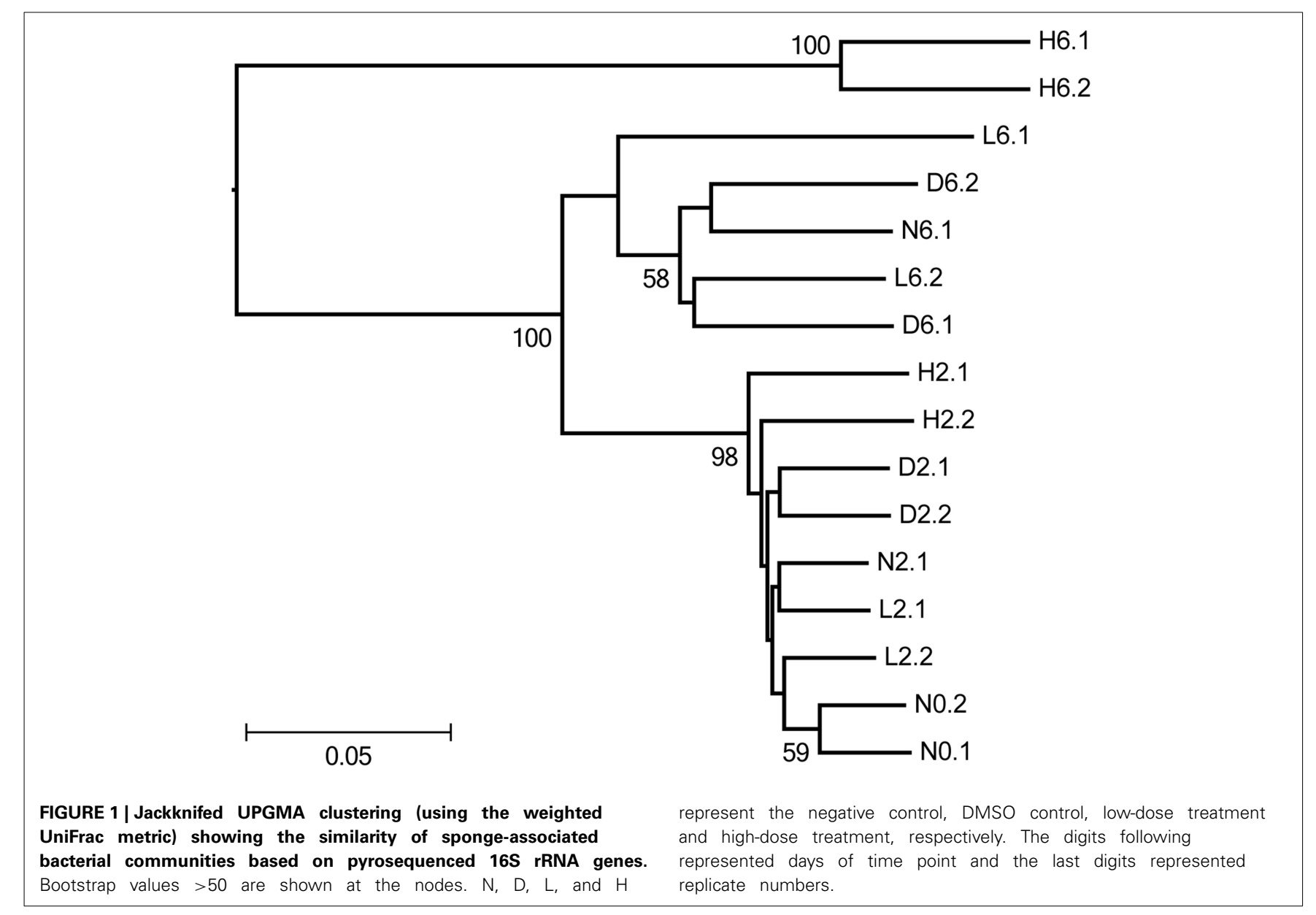

was remarkably enriched from $<1 \%$ in N6, D6 and L6 to $46.4 \%$ in H6. The bacterial communities obtained from the DMSO controls were highly similar to those of the negative controls, indicating that DMSO had no obvious effect on the bacterial community. These results showed that PBDE-47 could shift the structure of the sponge-associated bacterial community, resulting in a remarkable decrease in Proteobacteria and an enrichment for Firmicutes.

\section{PBDE-47 SHIFTED THE POTENTIALLY SYMBIOTIC SOB-DOMINATED COMMUNITY TO A HETEROTROPH-DOMINATED COMMUNITY}

At the genus level, up to $87.6 \%$ of the reads from the untreated sponge at day 0 (N0) were classified as unassigned Ectothiorhodospiraceae (Figure 2B). The 16S rRNA gene sequence (524 bp) had a similarity of $96.4 \%$ to a sequence from the spongespecific cluster database (ID: EF159783_SC153) (Simister et al., 2012). A phylogenetic analysis showed that it was located in a sponge-specific cluster (Figure S5), and the most closely related bacteria were Thioalkalivibrio (92\% identity to Thioalkalivibrio nitratireducens DSM 14787). Ectothiorhodospiraceae includes numerous thioautotrophic members that can oxidize reduced sulfur and acquire energy during this process. Our genomic analysis indicated that the dominant bacterium (the unassigned Ectothiorhodospiraceae in Figure 2) had the capacity to perform sulfur oxidation and $\mathrm{CO}_{2}$ fixation, thus playing a potentially symbiotic role by detoxifying sulfide in the host sponge (Tian et al., 2014a).

On day 6, the abundance of the sulfur-oxidizing bacterium (SOB) was significantly reduced from $41.2 \%$ in D6 to $3.6 \%$ in H6 ( $t$-test; $p<0.01$ ), while Clostridium was significantly enriched ( $t$-test; $p<0.01$ ) and occupied up to $43 \%$ of the community population in H6. Other significantly enriched genera in H6 ( $t$-test; $p<0.05)$ included Roseobacter (16.3\%), Polaribacter (3.2\%), and Owenweeksia $(6.0 \%)$, which were generally heterotrophic. These results indicated that PBDE-47 shifted the potentially symbiotic autotrophic SOB-dominated community to a heterotrophic community.

\section{SELECTIVE EFFECT OF PBDE-47 TREATMENT ON THE FUNCTIONS OF THE BACTERIAL COMMUNITY}

The metagenomic data for the microbial community of the treated sponge and the control included 426,468 and 441,416 raw reads with an average length of 506 and $507 \mathrm{bp}$, respectively. After quality control, 310,880 and 278,911 high-quality reads were annotated for the control and the treated sponge. The composition of functional genes in the control and PBDE-47-treated sponge metagenome were then compared.

In total, there were 12,548 functional categories (COG, KOG, and NOG) in the two metagenomic datasets, of which 108 categories were significantly increased or decreased (Fisher's exact 




FIGURE 2 | Taxonomic composition of the bacterial communities in the treated sponge samples and controls (with read numbers $\mathbf{> 1 0 0 0}$ ).

Classification of the pyrosequenced reads was performed using the RDP classifier against the Silva10.8 database at the (A) phylum and (B) genus levels. The minor group refers to genera representing $<1 \%$ in all samples. Sample abbreviations are provided in Figure $\mathbf{1}$. test; $p<0.01)$. Among the 48 significantly increased prokaryotic functional categories, 24 categories were involved in DNA synthesis and repair (including DNA mismatch repair and excision repair systems), multidrug efflux pumps (including the $\mathrm{Na}^{+}$driven pump and $\mathrm{ABC}$-type transporter pump), the $\mathrm{ABC}$ transporter for nutrient uptake (including the ABC-type sugar transport permease and periplasmic component), and chemotaxis signal transduction (Figure 3). These results indicated that the PBDE-47 treatment had a selective effect on the functions of the bacterial community in the sponge.

\section{DISCUSSION}

In the present study, we examined the effects of PBDE-47 treatment on the bacterial community structure in the sponge
H. cymaeformis, and the subsequent response of the community (in terms of the functional gene profile) to the stress induced by PBDE-47. The treatment had a time- and concentrationdependent effect on the bacterial community composition. Low$(10 \mathrm{ng} / \mathrm{L})$ and high $(1 \mu \mathrm{g} / \mathrm{L})$-dose treatments differed remarkably in terms of the effects on the bacterial community, and a long treatment duration intensified the effect of the high dose.

As described in a study examining heat treatment of the sponge (Webster et al., 2008), the inter-sponge variation was not recovered by DGGE screening. Similarly, in our study, the sponge Haliclona cymaeformis displayed extremely low intersponge and inter-tissue variations in bacterial community composition. Therefore, we selected a large parental sponge and generated small individual colonies for the PBDE-47 treatments. 


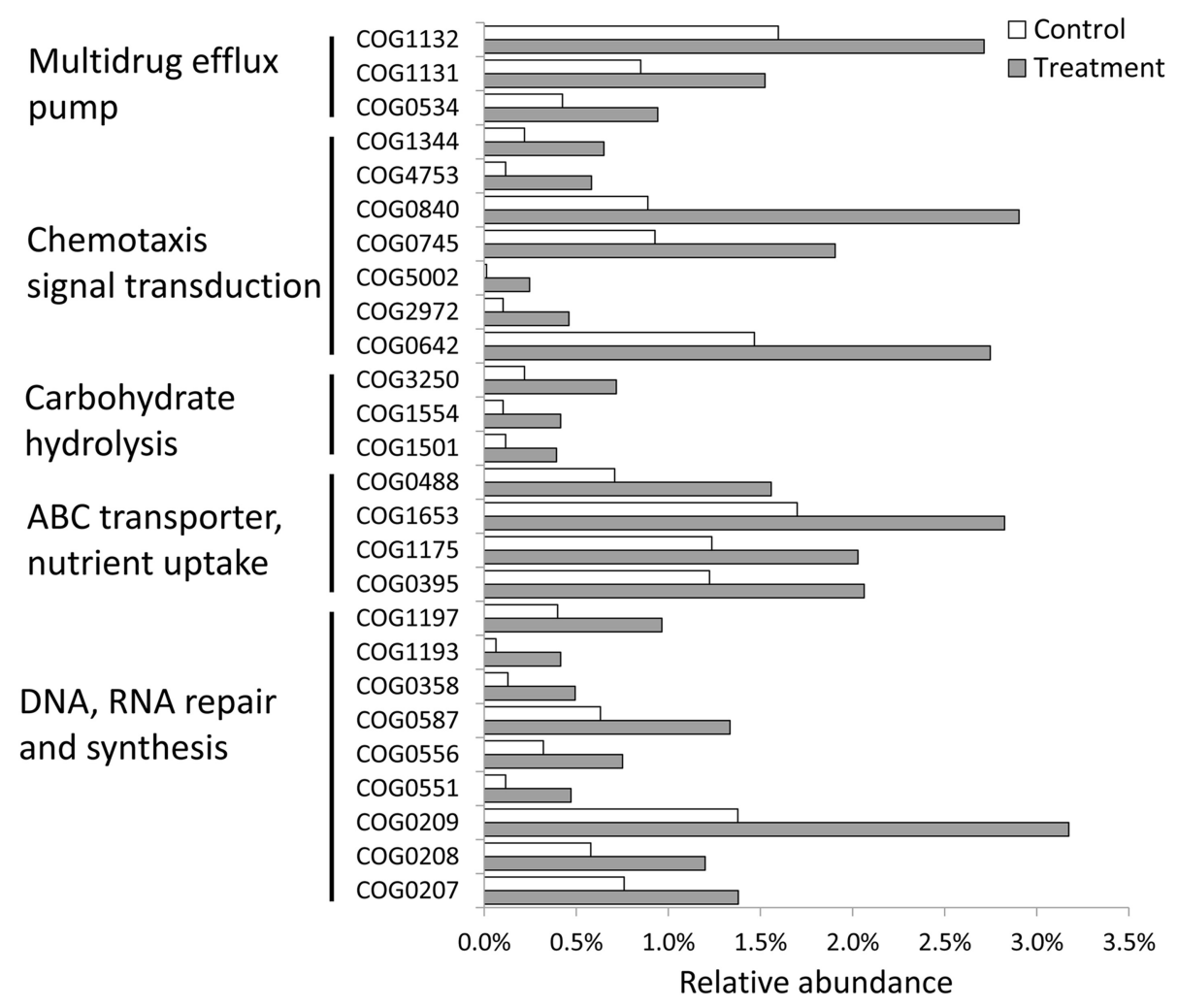

FIGURE 3 | Significantly changed (Fisher's exact test, $\boldsymbol{p}<\mathbf{0 . 0 5}$ ) functional genes in metagenomes for the control and PBDE-47-treated sponge samples. The $y$-axis represents the functional gene category, and the $x$-axis represents the relative abundance.

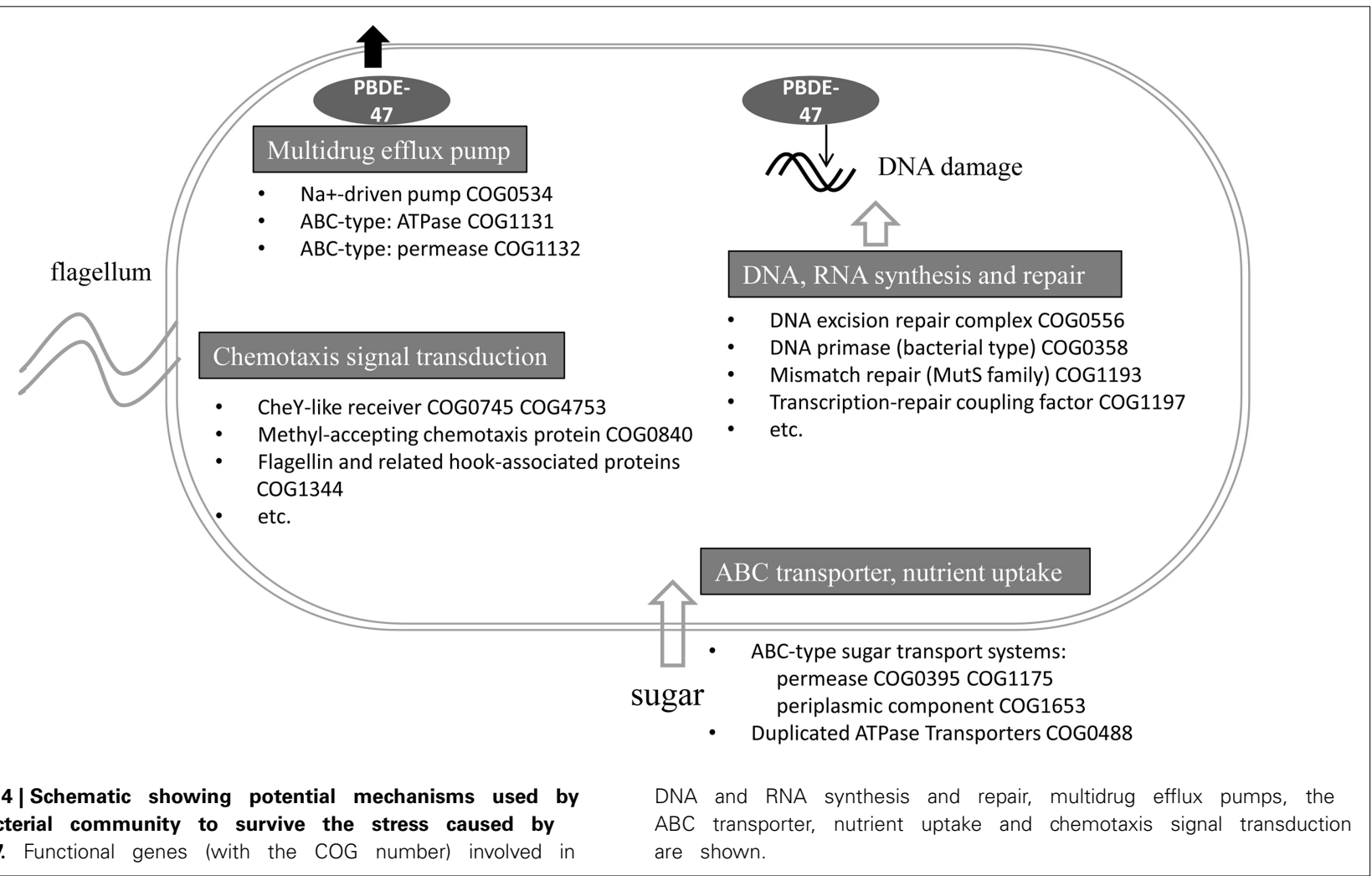


The results showed remarkable variations in the bacterial community caused by the high-dose treatments compared to the controls and low-dose treatments.

The high dose of PBDE-47 coupled with a long duration (6 days) of treatment substantially decreased the abundance of the unclassified Ectothiorhodospiraceae, which is a potentially symbiotic SOB in the sponge. Sulfur metabolism has been described in other sponges in which sulfur-reducing bacteria (SRB) generate sulfide (sulfate as the electronic acceptor) and SOB oxidize sulfide (Hoffmann et al., 2005; Taylor et al., 2007) and generate elemental sulfur and sulfate. In the present study, autotrophic SOB were dominant in the sponge H. cymaeformis and might play a symbiotic role by oxidizing sulfide as described in our previous study (Tian et al., 2014a). However, we showed that the SOB in sponge were remarkably decreased by the high-dose treatment with PBDE-47, which might disturb normal sulfur cycling and the symbiosis between the bacterium and the sponge host. The remarkable decrease in the dominant SOB by PBDE-47 treatment was similar to the effect of copper treatment observed in our previous study of the same sponge species (Tian et al., 2014b). Although there was no apparent necrosis in the PBDE-47-treated sponge samples, the color of the colonies became darker green in comparison to the controls, suggesting an effect of the treatment on the sponge-microbe consortium.

In contrast, the Clostridium and other heterotrophs were highly enriched in the community. A phylogenetic analysis (data not shown) revealed that the Clostridium in this study was located within the clusters of heterotrophic soil bacteria, including C. aestuarii, C. carnis, and C. sardiniense, suggesting a heterotrophic lifestyle of the Clostridium species in this study. The taxonomic analysis of the enriched functional genes showed that Clostridium is the dominant lineage in the taxonomic assignment (data not shown), which suggested that those beneficial genetic features assisted Clostridium survive under the stress of PBDE-47 treatment. Recent studies on the response of the microbial community to environmental stresses also showed a similar trend toward an enrichment of heterotrophs such as Firmicutes and Bacteroidetes (Webster et al., 2008; Tian et al., 2014b).

In terms of toxicity, PBDEs have been demonstrated to have harmful effects on the structure of DNA, and potential mechanisms underlying this effect have been documented in several studies (Zhao et al., 2002; He et al., 2008; Ji et al., 2011; Yan et al., 2011). PBDEs can covalently bind to DNA via quinone metabolites, resulting in the formation of a DNA-PBDE adduct. PBDEs can further cause DNA breakage and fragmentation. In addition to genotoxicity, PBDE-47 has also been shown to be cytotoxic, impacting cell viability (Zhang and Huang, 2005; He et al., 2008).

In the present study, the functional gene composition of the sponge-associated bacterial community was affected under PBDE-47-induced stress. Exposure to PBDE-47 selected for a set of functions that may facilitate survival during the stress caused by PBDE-47 (Figure 4). In our treatment experiment, the enriched functional genes related to DNA repair and synthesis might function to repair the DNA damage caused by PBDE-47; multidrug efflux pumps might function to transport the harmful PBDE-47 out of the bacterial cells; and chemotaxis genes might serve to guide bacteria to zones of minimal PBDE-47 concentration in the microenvironment of the sponge body. The selective effect of the treatment on the bacterial function suggested a survival mechanism of the bacterial community under the stress of PBDE- 47 .

In contrast to the effect of copper treatment (enriching for functions related to bacterial motility and chemotaxis, bacterial capsule synthesis, virulence, and bacterial signaling and regulation) on the same sponge species (Tian et al., 2014b), different functions (excluding bacterial motility and chemotaxis) such as DNA repair and multidrug efflux pumps were enriched by the PBDE-47 treatment, demonstrating that the toxicity and stress exerted by PBDE-47 on the bacterial community differs from that produced by copper.

\section{ACKNOWLEDGMENTS}

This research is supported by the National Basic Research Program of China (973 Program, No: 2012CB417304), State Key Laboratory of Marine Pollution (SKLMP) Seed Collaborative Research fund (CITYU12SC01), the Area of Excellence (AoE) fund (AoE04/04-II) and an award (SA-C0040/UK-C0016) from the King Abdullah University of Science and Technology granted to Pei-Yuan Qian.

\section{SUPPLEMENTARY MATERIAL}

The Supplementary Material for this article can be found online at: http://www.frontiersin.org/journal/10.3389/fmicb.2014. 00799/abstract

\section{REFERENCES}

Caporaso, J. G., Bittinger, K., Bushman, F. D., Desantis, T. Z., Andersen, G. L., and Knight, R. (2010a). PyNAST: a flexible tool for aligning sequences to a template alignment. Bioinformatics 26, 266-267. doi: 10.1093/bioinformatics/btp636

Caporaso, J. G., Kuczynski, J., Stombaugh, J., Bittinger, K., Bushman, F. D., Costello, E. K., et al. (2010b). QIIME allows analysis of high-throughput community sequencing data. Nat. Methods 7, 335-336. doi: 10.1038/nmeth.f.303

Chiu, J. M. Y., Po, B. H. K., Chan, C. Y. S., Lam, M. H. W., Qian, P. Y., and Wu, R. S. S. (2012). Polybrominated diphenyl ethers (PBDEs) alter larval settlement of marine intertidal organisms across three phyla via reducing bacterial abundance on the biofilms. Environ. Sci. Technol. 46, 7772-7781. doi: 10.1021/es300261c

Dayton, P. K. (1989). Interdecadal variation in an antarctic sponge and its predators from oceanographic climate shifts. Science 245, 1484-1486. doi: 10.1126/science.245.4925.1484

Dayton, P. K., Robilliard, G. A, Paine, R. T., and Dayton, L. B. (1974). Biological accommodation in the benthic community at McMurdo sound, Antarctica. Ecol. Monogr. 44, 105-128. doi: 10.2307/1942321

Edgar, R. C. (2004). MUSCLE: multiple sequence alignment with high accuracy and high throughput. Nucleic Acids Res. 32, 1792-1797. doi: 10.1093/nar/gkh340

Fan, L., Liu, M., Simister, R., Webster, N. S., and Thomas, T. (2013). Marine microbial symbiosis heats up: the phylogenetic and functional response of a sponge holobiont to thermal stress. ISME J. 7, 991-1002. doi: 10.1038/ismej.2012.165

Frank, D. N. (2009). BARCRAWL and BARTAB: software tools for the design and implementation of barcoded primers for highly multiplexed DNA sequencing. BMC Bioinform. 10:362. doi: 10.1186/1471-2105-10-362

Han, X. B., Lei, E. N. Y., Lam, M. H. W., and Wu, R. S. S. (2011). A whole life cycle assessment on effects of waterborne PBDEs on gene expression profile along the brain-pituitary-gonad axis and in the liver of zebrafish. Mar. Pollut. Bull. 63, 160-165. doi: 10.1016/j.marpolbul.2011.04.001

He, W. H., He, P., Wang, A. G., Xia, T., Xu, B. Y., and Chen, X. M. (2008). Effects of PBDE-47 on cytotoxicity and genotoxicity in human neuroblastoma cells in vitro. Mutat. Res. 649, 62-70. doi: 10.1016/j.mrgentox.2007.08.001

Hoffmann, F., Larsen, O., Thiel, V., Rapp, H. T., Pape, T., Michaelis, W., et al. (2005). An anaerobic world in sponges. Geomicrobiol. J. 22, 1-10. doi: $10.1080 / 01490450590922505$ 
Ji, K., Choi, K., Giesy, J. P., Musarrat, J., and Takeda, S. (2011). Genotoxicity of Several Polybrominated Diphenyl Ethers (PBDEs) and hydroxylated PBDEs, and their mechanisms of toxicity. Environ. Sci. Technol. 45, 5003-5008. doi: $10.1021 / \mathrm{es} 104344 \mathrm{e}$

Lam, C., Neumann, R., Shin, P. K. S., Au, D. W. T., Qian, P. Y., and Wu, R. S. S. (2010). Polybrominated Diphenylethers (PBDEs) alter larval settlement of marine benthic polychaetes. Environ. Sci. Technol. 44, 7130-7137. doi: 10.1021/es1012615

Lee, O. O., Wang, Y., Yang, J. K., Lafi, F. F., Al-Suwailem, A., and Qian, P. Y. (2011). Pyrosequencing reveals highly diverse and species-specific microbial communities in sponges from the Red Sea. ISME J. 5, 650-664. doi: 10.1038/ismej.2010.165

Lee, O. O., Wong, Y. H., and Qian, P. Y. (2009). Inter- and intraspecific variations of bacterial communities associated with marine sponges from san juan island, washington. Appl. Environ. Microbiol. 75, 3513-3521. doi: 10.1128/AEM.00 002-09

Li, C. W., Chen, J. Y., and Hua, T. E. (1998). Precambrian sponges with cellular structures. Science 279, 879-882. doi: 10.1126/science.279.5352.879

Mason, O. U., Hazen, T. C., Borglin, S., Chain, P. S. G., Dubinsky, E. A., Fortney, J. L., et al. (2012). Metagenome, metatranscriptome and single-cell sequencing reveal microbial response to Deepwater Horizon oil spill. ISME J. 6, 1715-1727. doi: 10.1038/ismej.2012.59

Niu, B. F., Fu, L. M., Sun, S. L., and Li, W. Z. (2010). Artificial and natural duplicates in pyrosequencing reads of metagenomic data. BMC Bioinform. 11:187. doi: 10.1186/1471-2105-11-187

Parks, D. H., and Beiko, R. G. (2010). Identifying biologically relevant differences between metagenomic communities. Bioinformatics 26, 715-721. doi: 10.1093/bioinformatics/btq041

Patel, R. K., and Jain, M. (2012). NGS QC toolkit: a toolkit for quality control of next generation sequencing data. PLOS ONE 7:e30619. doi: 10.1371/journal.pone.0030619

Pourmand, N., Elahi, E., Davis, R. W., and Ronaghi, M. (2002). Multiplex pyrosequencing. Nucleic Acids Res. 30:e31. doi: 10.1093/nar/30.7.e31

Pruesse, E., Quast, C., Knittel, K., Fuchs, B. M., Ludwig, W., Peplies, J., et al. (2007). SILVA: a comprehensive online resource for quality checked and aligned ribosomal RNA sequence data compatible with ARB. Nucleic Acids Res. 35, 7188-7196. doi: 10.1093/nar/gkm864

Rayne, S., Ikonomou, M. G., Ross, P. S., Ellis, G. M., and Barrett-Lennard, L. G. (2004). PBDEs, PBBs, and PCNs in three communities of free-ranging killer whales (Orcinus orca) from the northeastern Pacific Ocean. Environ. Sci. Technol. 38, 4293-4299. doi: 10.1021/es0495011

Reeder, J., and Knight, R. (2010). Rapidly denoising pyrosequencing amplicon reads by exploiting rank-abundance distributions. Nat. Methods 7, 668-669. doi: 10.1038/nmeth0910-668b

Shaw, S. D., and Kannan, K. (2009). Polybrominated diphenyl ethers in marine ecosystems of the American continents: foresight from current knowledge. Rev. Environ. Health 24, 157-229. doi: 10.1515/REVEH.2009.24.3.157

Simister, R. L., Deines, P., Botte, E. S., Webster, N. S., and Taylor, M. W. (2012). Sponge-specific clusters revisited: a comprehensive phylogeny of sponge-associated microorganisms. Environ. Microbiol. 14, 517-524. doi: 10.1111/j.1462-2920.2011.02664.x

Taylor, M. W., Radax, R., Steger, D., and Wagner, M. (2007). Sponge-associated microorganisms: evolution, ecology, and biotechnological potential. Microbiol. Mol. Biol. Rev. 71, 295-347. doi: 10.1128/MMBR.00040-06
Tian, R., Wang, Y., Bougouffa, S., Gao, Z., Cai, L., Bajic, V., et al. (2014a). Genomic analysis reveals versatile heterotrophic capacity of a potentially symbiotic sulfur-oxidizing bacterium in sponge. Environ. Microbiol. 16, 3548-3561. doi: 10.1111/1462-2920.12586

Tian, R., Wang, Y., Bougouffa, S., Gao, Z., Cai, L., Zhang, W., et al. (2014b). Effect of copper treatment on the composition and function of the bacterial community in the sponge Haliclona cymaeformis. mBio 5:e01980-e01914. doi: 10.1128/mBio.01980-14

Tomy, G. T., Palace, V. P., Halldorson, T., Braekevelt, E., Danell, R., Wautier, K., et al. (2004). Bioaccumulation, biotransformation, and biochemical effects of brominated diphenyl ethers in juvenile lake trout (Salvelinus namaycush). Environ. Sci. Technol. 38, 1496-1504. doi: 10.1021/es035070v

Wang, Q., Garrity, G. M., Tiedje, J. M., and Cole, J. R. (2007). Naive bayesian classifier for rapid assignment of rRNA sequences into the new bacterial taxonomy. Appl. Environ. Microbiol. 73, 5261-5267. doi: 10.1128/AEM.00062-07

Webster, N. S., Cobb, R. E., and Negri, A. P. (2008). Temperature thresholds for bacterial symbiosis with a sponge. ISME J. 2, 830-842. doi: 10.1038/ismej. 2008.42

Webster, N. S., Webb, R. I., Ridd, M. J., Hill, R. T., and Negri, A. P. (2001). The effects of copper on the microbial community of a coral reef sponge. Environ. Microbiol. 3, 19-31. doi: 10.1046/j.1462-2920.2001.00155.x

Wolkers, H., Van Bavel, B., Derocher, A. E., Wiig, O., Kovacs, K. M., Lydersen, C., et al. (2004). Congener-specific accumulation and food chain transfer of polybrominated diphenyl ethers in two Arctic food chains. Environ. Sci. Technol. 38, 1667-1674. doi: 10.1021/es030448a

Yan, C., Huang, D. J., and Zhang, Y. M. (2011). The involvement of ROS overproduction and mitochondrial dysfunction in PBDE-47-induced apoptosis on Jurkat cells. Exp. Toxicol. Pathol. 63, 413-417. doi: 10.1016/j.etp.2010. 02.018

Zhang, C. X., and Huang, K. X. (2005). Apoptosis induction on HL-60 cells of a novel polysaccharide from the mucus of the loach, Misgurnus anguillicaudatus. J. Ethnopharmacol. 99, 385-390. doi: 10.1016/j.jep.2005.02.033

Zhao, S., Narang, A., Gierthy, J., and Eadon, G. (2002). Detection and characterization of DNA adducts formed from metabolites of the fungicide ortho-phenylphenol. J. Agri. Food Chem. 50, 3351-3358. doi: 10.1021/jf0116294

Conflict of Interest Statement: The authors declare that the research was conducted in the absence of any commercial or financial relationships that could be construed as a potential conflict of interest.

Received: 18 November 2014; paper pending published: 12 December 2014; accepted: 27 December 2014; published online: 14 January 2015.

Citation: Tian R-M, Lee OO, Wang Y, Cai L, Bougouffa S, Chiu JMY, Wu RSS and Qian P-Y (2015) Effect of polybrominated diphenyl ether (PBDE) treatment on the composition and function of the bacterial community in the sponge Haliclona cymaeformis. Front. Microbiol. 5:799. doi: 10.3389/fmicb.2014.00799

This article was submitted to Microbial Symbioses, a section of the journal Frontiers in Microbiology.

Copyright (C) 2015 Tian, Lee, Wang, Cai, Bougouffa, Chiu, Wu and Qian. This is an open-access article distributed under the terms of the Creative Commons Attribution License (CC BY). The use, distribution or reproduction in other forums is permitted, provided the original author(s) or licensor are credited and that the original publication in this journal is cited, in accordance with accepted academic practice. No use, distribution or reproduction is permitted which does not comply with these terms. 